\title{
Why Did It Happen to Us? Confronting the Individualization of Racism in a Historically White Afrikaans Institute of Higher Learning
}

\author{
Gregory Alexander \\ Department Postgraduate Studies of Education, Faculty of Humanities, Central University of Technology \\ alexanderg@telkomsa.sa \\ Juliet Ramohai \\ Department of Psychology of Education, Faculty of Education, University of the Free State, South Africa \\ RamohaiJ@ufs.ac.za \\ Annalene Van staden \\ Department of Psychology of Education, Faculty of Education, University of the Free State, South Africa \\ VanStadenAJ@ufs.ac.za
}

\section{Doi:10.5901/mjss.2014.v5n27p1207}

\section{Abstract}

This paper is an attempt by three lecturers at a Historically White Afrikaans institution of higher learning in South Africa to reflect critically on their experiences with regard to accusations of racism levelled against them. The accusations mentioned may be viewed as the possible aftermath of the Reitz incident in which four White Afrikaans university students were accused of racism. Through narratives, the writers outline their accounts of events which transpired during a very turbulent time at this university. The 'dark period' incident (pseudonym) as our story is known, sparked an outcry from us as lecturers and a studentlecturer to express our portrayal and interpretations of events within the context of the transformation at our institutions. This we envisaged, might bring about closure to the whole debacle regarding our experiences of the 'dark period' incident in which accusations of racism were made against us.

Keywords: institute of higher learning, racism, white afrikaans, narratives

\section{Introduction}

Any form of racism, whether in the form of violence or humiliation, should be condemned. The focus of our paper is on how we, as lecturers at a Historically White Afrikaans University, grappled with notions of racism, in particular that of interpersonal and personal racism (Report of the Ministerial Committee on Transformation and Social Cohesion and the Elimination of Discrimination in Public Higher Education Institutions 2008) and how we, through our narratives, engage in a process of reflecting on our past and unlearning behaviour that challenges any form of racism and/or discrimination. In essence, this paper draws on our reflections surrounding the 'dark period' racial incident, prevailing interactions and accompanying actions undertaken. Our narratives thus express our account of events which emerged individually and through a process of dialogue which served as a basis for collegial debriefing, meaning-making of our experiences and establishing closure to our racialised encounter.

First, we provide the background to the 'dark period' incident so as to orientate the reader to the site where implicated lecturers and students rendered their community engaged activity. Secondly, we conceptualise our portrayal of racism and the racist accusations levelled against us within the sense-making framework. In addition, the emergence of key issues emanating from our narratives and our reflections therein are outlined. Furthermore, we explore things that we could have done differently, highlighting the lessons learnt through our experiences and also provide an outline of how as staff members, we envisage moving beyond our own defensiveness. Finally, proposed interventions that Higher Education Institutions might consider in a similar situation to which we were exposed are discussed. 


\section{Conceptualising our Portrayal of Racism Levelled Against us within the Framework of the Report of the Ministerial Committee}

The February 2008 public broadcasting of the Reitz Residence incident that took place at the University of the Free state in which four young white Afrikaans male students were implicated as racists, laid the context for a Ministerial investigation into issues of transformation, social cohesion and the elimination of discrimination in public Higher Education Institutions (Report of the Ministerial Committee 2008). This investigation revealed a deeper understanding of issues relating to racism and the underlying assumptions constituting discriminatory practices in institutions of higher learning in South Africa. International efforts (Declaration on Education for Peace, Human rights and Democracy) in Geneva, October 1994, highlighted a global concern with the manifestations of violence, racism, xenophobia, aggressive nationalism and violations of human rights in all spheres of society (Sigh 2005).

Racism, as conceptualised in this paper is viewed as a basis for managing individual relations in everyday life, and is underpinned by stereotypes, images, attributions and explanations used to justify and account for the exclusionary and discriminatory treatment of groups of people (Report of the Ministerial Committee 2008). Everyday racism, as perceived by Essed, is an active and cumulative process of daily, familiar and repetitive practices that reproduce racial domination in interpersonal and institutional endeavours; thus, a complex of practices operate through heterogeneous relations (race, class, gender, etc.) that seem to "activate underlying power relations" and "become part of the reproduction of the system" (Robus and Macleod, 2006, 468). The interwovenness of entrenched ideas and practices on human agencies are constructed via social encounters present and experienced in everyday practices (Essed in Alexander, Van Wyk, Bereng and November 2009).

According to the Anti-Racist Network in the Report of the Ministerial Committee (2008) the 'naming' of racism forms part of a broader development whereby racism is perceived as an individual phenomenon that functions 'only at the level of the individual'. Bell (2007) postulates that racism is not only embedded in overt, conscious prejudice and discrimination but also through the unconscious attitudes and behaviours of a society that presumes an unacknowledged but pervasive white cultural norm. Racism in the context of South Africa refers to the manner in which the social system advantages one group, people taken as White in relation other groups, and which privileges 'Whiteness' (such as Caucasian physical characteristics) over 'Blackness' (Francis et al 2003).

An unpacking of the term 'racism' is crucial to the conceptualization of our account of racism. We view a deeper understanding of the racist accusations against us as lecturers as an opportunity to interrogate our experiences of the incident and to further serve as a mechanism in confronting our own internal racist tendencies and deep rooted thoughts of racism. People's ability and willingness to confront their own racist tendencies is clearly outlined in the Report of the Ministerial Committee as an issue to consider in the racially depleted higher education in South Africa.

The individualisation of racism, both at the level of the victim and that of the perpetrator, impacted on the ability of the victims, the two lecturers (White and Coloured) and student-lecturer (African), to stand together and use the power of the group to stamp out the scourge of racism which threatened the productivity of the discipline in which the three victims offer their services. This paper is then a collaborative effort from three lecturers in the Faculty to express their experience with regard to allegations of racism.

\section{Background to Happy Valley}

Through the mandate of the Community Services Directorate's community engagement initiative, two lecturers, a studentlecturer (currently a staff member) and a group of African, Black and White B.Ed. Honours students from the Department of Psychology of Education became involved in Happy Valley a non-governmental organisation, which houses HIVIAIDS infected and affected orphans. In consultation with the management staff of Happy Valley it was agreed that the students who were enrolled for a course in Support Teaching (identification, assessment and development of support programmes for learners with special education needs) would assist these school-going children (Grades R to seven), with specific barriers to learning and development. A clear modus operandi and protocol with regard to the assessment of learners were outlined by the coordinating two lecturers.

In constructing our notion to and understanding of race within the conceptualisation of this paper, it is useful to name race as social construct within the confines of the South African context (Francis, Hemson, Mphambukeli and Quin 2003). Racial categorisation White, Coloured, African) are further used to refer to the two lecturers (White and Coloured) and the one student-lecturer (African).

Our encounter specifically highlights and demonstrates similarity to what is coined in the Report of the Ministerial Committee (2008) regarding the origin of racism: 'False beliefs about race have come to be so significant that they play a 
real role in determining relationships of human beings with each other'.

Unconsciously, the two lecturers and the student-lecturer's experiences of the Happy Valley incident, culminated in an experience defined as racism and characterised by feelings of fear, mistrust, anger, abandonment, confusion and disloyalty.

The correspondence forwarded to the White and Coloured lecturers respectively, as well as a senior manager of faculty via an individual identifying himself as a member of a certain political party, who raised a concern about the events of the day allergedly reported to him by one student who was involved at the 'happy valley'read as follows:

3.1 (Below is the concealed communique forward by a senior manager to the two staff members implicated in the racial incident)

Dear Dr X-"pseudonym" (Head of Department)

I attach a copy of an e-mail I received from a Mr Y "pseudonym" (member of a certain political party) that speaks for itself. I regard this as a very serious matter and would like you to urgently attend to the matter and to report back to me today still.

Regards

Senior manager.

3.2 (Below, the concealed communiqué sent by an individual of a certain political party)

Good day Gentlemen,

I wish to bring to your attention a very serious issue on racial disharmony in the university.

On 21 April 2008 a group of students led by Dr Joe and Dr Grace visited Happy Valley in Bloemfontein for their practicals. The students were separated in terms of colour. The white students accompanied by some of the lecturers got a combi first and left for Happy Valley. The black students had to wait for an hour before they could be transported. In terms of numbers they were all together 16 students, 11 white and 5 black.

On arrival, the black students found their white counterparts sitting in a nicely dressed and decorated room, well warmed up and served with tea. The black students were taken to a different room where they were to work from. The day was cold. The room they were placed in was very cold and very stinky, without chairs. They were later supplied with plastic kindergarten chairs.

Later, another round of tea was served in the room where the white students were sitting. The black students were only informed of the tea when they had finished and all the cookies served were finished.

This info' was confirmed by Ms Z "pseudonym" of 'Happy Valley'.

On returning, bundled as they went, blacks behind as before, one of the students expressed her disgust at what had happened. One of the two lecturers with them tried to downplay the events, but all the students expressed their uttermost unhappiness. The lecturer who was driving the combi almost caused an accident thereafter.

Now a few weeks later, it is said that the white students no longer want to attend these practicals, WHY??????

I listened with pain when the university was denying that there was open racism at the university. Here is a specific situation. The university should demonstrate its intolerance to racism; otherwise all talk is empty talk.

It would be worthwhile investigating. There could be a serious case of racial misconduct brought against lecturers in the Education Department.

The same information shall be passed to other interested parties.

Have a good day.

$\mathrm{MrY}$

(The third lecturer in our narrative fulfilled the role of student and lecturer at the time of the incident, as she was involved in the project as a student but was at the time working as a temporary junior lecturer at the department of Psychology of education. The above correspondence was only forwarded to two lecturers who are permanent staff members)

Notably, we as the two accused lecturers (White and Coloured) interpreted the communique from the senior manager as threatening - he already made a 'guilty verdict' on our involvement in the incident. The second correspondence directed to us from an individual of a certain political party, was experienced with shock and confusion. We felt that our 'good deed' to the community was undone by African students ( whom we felt were behind the whole incident) who have not genuinely engaged with the Happy Valley activity as a community based learning experience, but who went there with other agendas. 


\section{Towards a Theoretical Underpinning}

Underlying the narration of our experiences regarding the 'dark period' incident, is our intention to make sense of the whole debacle with the aim of moving beyond the effects brought about by the incidents. As thus we engage, as our theoretical underpinning the sense-making theory (Weick, Sutcliffe and Obstfeld 2005) which postulates that human beings try to make sense of their reality of everyday living by asking themselves questions like: what is the essence in this? 'Why do things' happen the way they do? (Finding meaning in behaviours) and what should we do? (Trying to take action on behaviour). These are the questions that as three lecturers we are asking ourselves in this paper and believe that that the exercise will help us to challenge our own thoughts and behaviours which will in turn help us to create a healthy and productive work environment. We understand that at the beginning of the incidents, we immediately put ourselves in the victims' state and avoided to deal with the issue positively. With this paper we are attempting to understand the circumstances that may have contributed to such a huge misunderstanding instead of blaming one another for the incident.

\section{Emergence of Key Issues of our Narratives}

\subsubsection{Fear, mistrust and anger}

Fear, mistrust and anger seem to be overarching emotions experienced by everyone involved, especially anger, due to the life-histories of mainly the three lecturers which were unknown to the author who wrote the e-mail.

Hope: "...the anger that I felt when I came to know that I was being suspected of something I didn't do was so great, that I felt a lot of hatred towards the lecturers. This anger (hatred) even extended to everybody who is white because I began to believe that white people hate ME! The fear that I felt, that I was going to lose my job was great. I was still on probation and anything could happen to me (which really did). I could lose my job..."

Grace: I experienced different emotions ... at some stage I really got angry ... I couldn't understand why somebody would like to hurt us in such a way - thinking of it, of all the lecturers working in the department; we are the only ones who actively engage in community service ... and students even signed consent forms - it was a voluntary project; nobody was forced to take part - so was this done intentionally?... initially, we didn't suspect the students ... then the email came to threaten us, followed by a black student coming to see us and implicating two other black students who, according to the student, were behind this and were inciting the other students ... if it were not for the video that actually proved our innocence, we would have been 'sacrificed' and certainly would have lost our jobs.

Joe: The fact that my White colleague and I were the first in the School of Education to expose our students to an activity involving community engagement and the effort accompanying it, felt as if students participated in the event with other unrelated agendas and motives in mind - this was interpreted by me as students being disloyal to the cause (supporting HIV/Aids children with barriers to learning and development), unaffectionate and inconsiderate of the environment in which Happy Valley was located. After all in my thinking, students were briefed beforehand regarding the aim of the activity and should have gone to the site applying an open mind - it was about getting your hands dirty. I expected that the student-staff member would have, at some stage, 'defended' us as the accused parties. Her silent and somewhat distanced stance disappointed me.

The anger felt by us three lecturers was mainly due to the unexpected accusations of racism against us. We all never expected any come back from what we considered to be a community engaged activity because to us everything done was fulfilling. The good intentions however, seemed to have been undermined by those who laid racist accusations against us. This is angering on the part of the coordinators. On the other hand, the student-lecturer feltthe accusations against her were unrooted and unjustifiable and this brought about feelings of anger and fear -the fear of losing our jobs was the greatest.

\subsubsection{Management responsibility}

From the literature it is evident that there exists a culture of silence and fear among Higher Education faculty members and they fail to address complex social issues such as diversity, discrimination and transformation, although they profess to work toward equity and social justice (Rusch and Horsford 2009).

Hope: I always feel that Management has failed me. According to me, this matter was not well handled. Management failed to meet with the suspected group to get their views. Because the truth of the matter was not established, fertile 
soil was prepared for suspicions, mistrusts and blame. I feel that Management could have met all the concerned parties after they had received the e-mail to discuss this issue in a transparent manner.

Grace \& Joe: Management has definitely failed us - they failed to take responsibility in facilitating a process of providing closure to the incident. Moreover, from the e-mail that was sent to us, it seemed as if we had already 'been tried and found guilty'. No one helped us; we had to stand up for ourselves - even to date (after we had had to prove our innocence), no one wanted to discuss it further or investigate the incident, despite our request to arrange for open discussion between us and the students involved.

From the narratives, it seems that the role of management in enhancing social cohesion within HE is crucial. We feel that management could have intervened, stresses the point that management has a role in facilitating processes of transformation and be at the forefront in maintaining social stability.

\subsubsection{Racism}

Racism is a complex social issue that does not only function through overt, conscious prejudice and discrimination, but also through the unconscious attitudes and behaviours of members of society (Griffon 2007). Each time society conjures up race as a construct to explain the historical, political, social and psychological status of people, racism is re-inscribed and underwritten - keeping it alive and 'breathing' (Franchi 2003).

Hope: What still hurts most is the fact that I was accused of something I COULD NEVER THINK OF DOING (I AM NOT CAPABLE OF); MORE THAN THAT, I DIDN'T DO IT. Is it because of my skin colour or because people wanted to get rid of me in this department and they saw a good opportunity? ... Just like the issue of dominance... I felt as if the two lecturers already had a problem with African people; that is why we (myself and the other African students) became the first suspects. As an African person, when I heard the story of the e-mail, I had already thought that we would be suspected because I always felt that white people do not really like us (African people), partly due to my initial experiences in the department in which I felt I was being marginalised.

Grace: I experienced the incident as reverse racism - students were looking forsomeone to blame after Reitz - was it because of our skin colour - there were definite intentions to make us look guilty.

Joe: When I read the correspondence of the senior manager and the person of a political party, I got a sense that these individuals already stigmatized me as a racist - worst was that the fact that the students I took on the field trip made such clear observations in terms of what they perceived as racism. What could be noticed from these narratives is that an event which was misinterpreted as racist ended up as a racial issue. The two lecturers' outcry that they were accused of racism were internalized as the Africans students being the main culprits. On the other hand, the student-lecturer also ended with "is it because I am black"?

\subsubsection{Dominance, oppression and marginalization}

Historically White Afrikaans institutions of higher learning are often marked by patriarch relationships in which dominance, oppression and marginalisation are portrayed in management styles as experienced by staff members. As a result, both groups (students and staff members) are subjected to aspects associated with vertical oppression.

Hope: ... the whole issue felt as if some people were favoured while I was victimised. The fact that the two lecturers had access to all the communiqués between the person who wrote the e-mail and the authorities while I, the suspect, was kept in the dark made me feel oppressed. It seemed to me as though they deserved the right to know what was going on because they were superior, deserving and were regarded as innocent already, while I was 'guilty'. I felt so powerless because I wasn't even given the chance to defend myself.

Grace: We were denied the opportunity to explain the day's events to the students and were even forbidden to discuss this incident with the students, so in a sense, we were definitely marginalised and oppressed by our senior manager.

Joe: During the interactions, Grace and myself had with the senior manager, I realised that he was using his position as authority figure to basically instruct us on how we need to management the incident- the position of power during our engagement was much evident, even alluding to himself as the person who will make the decisions on on how this matter would be dealt with.

Dominance forms an integral part of oppression. All three of us felt that in one way or the other, were being oppressed by our senior managers and that they denied us a chance to stand up for themselves. 


\subsubsection{Stereotypes still exist}

Stereotyping refers to prejudices, values, beliefs, biases, feelings, assumptions and attitudes that people may have within themselves - which may/may not be expressed to others, but operate within the individual (Report of the Ministerial Committee 2008).

Hope:...that regard people of colour as dishonest, untrustworthy and bad!!! I always fail to understand why only people of colour (black students) were the only ones who were suspected when there was another group of white students. Besides, I was already a lecturer at the time, but I didn't have access to the e-mails which apparently implicated me. It was as if I was being judged even before the truth of the matter could be established. Was it because I am black?

Grace \& Joe: Not knowing our backgrounds, where we come from, being unaware of ou contributions to society as a whole, we presumed that students stereotyped us as typically being reared in environments where issues of race and racism are being perpetuated.

We are not contemplating that we are free of any stereotypes, but our historical, socio-economic backgrounds and how we moved forward in our careers and personal lives in attempting to 'rid' ourselves from this type of behaviour is perceived as a worthwhile effort by us.

\section{What Could Have Been Done Differently?}

According to Bell (2007) through internalised racism, members of the dominant group often indulge in discriminatory acts against other people because to them, the status quo is normal; thus, they often fail to understand why some events are interpreted by 'others' as discriminatory. A contrary situation may occur, given our country's history of oppression and racism. Some people are more sensitive and because they may have internalised racism, they are more likely to experience such incidences as racism. Reflecting on the day's happening this is what we have experienced:

Grace: Involving students in community projects without thoroughly preparing them to deal with the harsh realities they may find can have severe consequences and as has been demonstrated, can even be perceived as racism. Given our country's past, it is imperative that students, before engaging in community service projects, should be thoroughly prepared; a possible solution is workshops on diversity issues. We have to become aware of, respect and accommodate one another's cultural beliefs and differences and in addition, the faculty/university has to play a central role in organising these kinds of initiatives. Moreover, because I always treat all people equally, this could perhaps have clouded my judgment of the incident, thus, preventing me from seeing that this incident could have been interpreted as a racial incident.

Hope: Our history in this country holds very fertile soil for racist thoughts. If we were not in a country where racism was such a big issue, interpretations of this kind wouldn't have occurred. We could have perhaps put the blame on the centre for not hosting us well, but history intervened and the effects were just too great to handle, even now.

What could have been done differently? I believe projects such as this should be conducted following a formal procedure that is developed and monitored by the community service department. In this way, it can never be the responsibility of lecturers alone to deal with the technical part of the project.

Joe: Although students were designated the responsibility of making a choice of in which vehicle they wished to be transported (group cohesion and cultural identification), I will definitely give more thought to creating more diverse student groupings, especially with regard to the planning of future community engagement initiatives. Our internalised unconscious prejudiced position regarding the possible role of our colleague, the student-lecturer in the incident polluted our making an objective judgement of her involvement/non-involvement. Surely, if we had not allowed our biased thinking to cloud our judgement with regard to the African student-lecturer member, we would have had an understanding of her account of events.

\section{Lessons Learned -The Way Forward}

As traumatising as this event was, it gave us a chance to reflect upon and interrogate our deep- rooted and unintentional racist inclinations towards individuals from diverse cultures. It also afforded us the chance to engage in discourse that helped us to unlearn our privileges, debrief and bring closure to the matter. This required effort on our part because we still bottled up the hurt and trauma that the incident had brought. In this regard, Rusch and Hosford (2009) reiterate that: unlearning is no simple process for adults ... it requires adults to acknowledge that they are blindly ignorant (of their feelings)... unlearning requires the exploration of personal and deeply imbedded paradigms, personal habits of mind and 
reordering of assumptions.

Grace: Given a different place and a different time, I am sure that the student(s) wouldn't have reacted in the way they did ... It did made me realise that because of 'apartheid' and the immense pain it caused, so many people are still hurting and that this has led to people internalising racism to such an extent that even the most harmless intentions can be perceived by some as racism. But on the other hand, it has sensitised my feelings very much; now, I think twice when it comes to anything that could possibly be interpreted in the wrong way.

Hope: I believe that change needs a considerable degree of intentionality. It was difficult for me to put behind (to move away from) the fact that I was accused of something that I did not do. This made me hate the system and the people in general, particularly those in my department. Not only was my image tainted (that I called people 'racist' in an incident that was not perceived to be racist), but that my integrity towards my department and my colleagues was put at stake. However, holding grudges was not going to help because I could not be productive if I held on to past issues. This took a lot of courage; I realised that in a way, I was also becoming racist because I saw the lecturers as whites illtreating me because I am African. To change this perception needed a great deal of intention on my part.

Joe: Emanating from the correspondence forwarded to the White and Coloured staff members, the assumption was that it was the African student(s) who registered their grievances with an outside political party. Referrals to the vehicle in which the African students and African student-lecturer member were transported (a White staff member being the driver), further raised suspicion about the involvement of these individuals. What we as white and Coloured staff members were not aware of is that our African student-staff member had not received the communique that was forwarded to us.

\section{Moving Beyond Defensiveness}

Griffin (2007) states that it is very difficult for people to confront their own prejudices because in doing so, a person has to question what is familiar, comfortable and unquestioned.

Hope: I sometimes feel that I became defensive when this issue erupted - this denied me time to think that, in a way, I could have instigated the perception that we were treated unequally. Instead of complaining directly to the lecturers involved, we discussed our dissatisfaction amongst ourselves and thus perceived this incident as racist. I now realise that the confusion could have been avoided.

Grace: In retrospection, I was trying to defend myself the whole time, wanting todemonstrate that there were no racial intentions involved, that prevented me from looking objectively at the day's happenings, contrary to the students who perhaps might have internalised the incident as racist. This, according to me, has been exacerbated to a great extent by the Reitz incident.

Joe: After congesting everything that occurred over the few days, I began to realize that I did nothing wrong- maybe there is some aspects pertaining to the planning of the activity I could have approached in another way. I reached a stage where I convince myself that I need to draw on my previous experience of such incidents- afterall Iwas extensively involved with the integration and amalgamation of schools in the Northern Cape province of South Africa - this matter I need to tackle head- on and think of my own "survival" and not of the reputation of the senior manager or the image of the university.

\section{Possible Interventions Higher Education May Take into Account}

Rusch and Horsford (2009) outline certain transformative actions HEls might consider when challenged with institutionalised racism, namely:

- Integrating multiple narratives: The promotion of discussion as a tool for looking at multiple and diverse ideas and facts, suggesting that opposing ideas have the possibility of enriching one's views; the process of "intellectual teamwork" is a contribution that might be made by faculty management. In other words, forums for discourse (narration and anecdotes) via colour or race-based ontological and epistemological assumptions should be set up. Constructive talk, transformative collective thought and intellectual teamwork regarding issues of race and complex social issues suggest a process of engaging with one another's world views. Robust and Macleod (2006) are in agreement with the latter and see discourse as a constructive mechanism in describing one's social world in which reality is conceptualised. These researchers also propose that 
Discursive Psychology as an increasingly popular model for investigating issues of racism creates opportunities for reconstructing and even transforming identities.

- Workshops and staff development activities: Mapesela and Hay (2006) and Alexander (2004) also suggest that workshops and staff development opportunities with a focus on diversity, race awareness and change management might address issues of culture and identity, thereby changing the attitudes among staff. These might work if members make a concerted effort to change their own attitudes.

- Facilitative process: Alexander (2004) posits that any event which aims to bring about racial harmony and solidarity amongst individuals of diverse cultural backgrounds needs to be facilitated through clear processes, structures and expert facilitators. The 'cultivation of humanity' should be central to courses and programmes at undergraduate level which might give an indication as to how well managers at $\mathrm{HE}$ are facilitating the change process (Walker 2005).

- Change management: Tam (1999) proposes a strategy of 'managing change by changing management' which might be applied in HE. This intervention suggests re-assessing the ways of conducting core business in $\mathrm{HE}$ and adjusting crucial aspects of its structure and operation.

- Courses on citizenship: Waghid (2004) is of the opinion that courses, especially at the level of HE, need to be structured around values and principles which teach students to become democratic, socially just, equitable, egalitarian, non-racist and non-sexist, dignified, open, accountable, respectful, reconciliatory and law-abiding, thus providing education for citizenship.

- A compulsory course in Social Justice Education: There is a need in the Faculty to implement a course on social justice education which could address in particular issues relating to sexism, racism as forms of oppression which explores student and staff experience using specific concepts as tools for that exploration (Francis et al 2003).

\section{Conclusion}

Alas the overall state of transformation in Higher education, especially as reflected in a White Afrikaans institution, our experience of racism levelled against us is greatly the consequence of racism being endemic with the institution. In our view the aftermath of the Reitz Residence incident created an atmosphere of fear, mistrust and anger amongst lecturers and students and between the community and university. Our narratives, which emerged individually through a process of dialogue voice our experiences of the Happy Valley racial incident and also serve as a platform in bringing about closure to the event- this indeed was a mechanism of confronting also our own deep rooted feelings of individualised racism.

\section{References}

Alexander, G. (2005). The design and evaluation of a staff development programme for amalgamated schools in the Northern Cape. Ph.D.Thesis, Unpublished. Bloemfontein: University of the Free State.

Alexander, G., Van Wyk., Bereng, M.T., \& November, I. (2009). Legitimate Peripheral Participation (LPP) -The case for recognition of prior learning sites and knowledges in South Africa's transforming education system. Teaching and Teacher Education, 26: 4552.

Bell, L. (2007). Theoretical foundations for social justice education. in: M. Adams, L. Bell and P. Griffin (Eds),Teaching for Diversity and Social Justice, (pp.1-14). New York/London: Routledge.

Francis, D., Hemson, C., Mphambukeli, C.T. \& Quin. J. (2003). Who are we? Naming ourselves as facilitators. Journal of Education, 31: 137-150.

Griffin, P. (2007). Conceptual Foundations for Social Justice Education, in: M. Adams, L.Bell \& Griffin (Eds) Teaching for Diversity and Social Justice (pp.35-66). New York/London: Routledge.

Mapesela, M., \& Hay, H.R.( 2006). The effect of change and transformation on academic staff and job satisfaction: A case of a South African University. Higher Education, 52: 711-747.

Report of the Ministerial Committee on Transformation and Social Cohesion and the Elimination of Discrimination in Public Higher Education Institutions (2008). Pretoria: Department of Education.

Robust, D., \& Macleod, C.(2006).'White excellence and black failure': The reproduction of racialised higher education in everyday talk. South African Journal of Psychology, 36(3): 463-480.

Rusch, E.A.., \& Horsford, S.D. (2009). Changing hearts and minds: the quest for open talk about race in educational leadership. International Journal of Educational Leadership, 23(4): 302-313.

Singh, K. (2005). Non-discrimination and equal educational opportunities: UNESCO's normative action. in: Russo,

C.J., Beckman. J. \& Jansen, J.D (Eds). Equal Educational Opportunities: Comparative perspectives in educational law (pg. 55-76). Pretoria: Van Schaik Publishers. 
Tam, M. (1999). Managing change involves changing management: implications for transforming higher education. Quality in Higher Education, 5 (3): 227-231.

Waghid, Y. (2004). Compassion, citizenship and education in South Africa: An opportunity for transformation. International Review of Education, 50 (5-6): 525-542.

Walker, M. (2005). Rainbow nation or new racism? Theorizing race and identity formation in South African higher education. Race, Ethnicity and Education, 8 (2): 129-146.

Weick, K.E., Sutcliffe, K.M., \& Obstfeld, D. (2005). Organising and the process of sensemaking. Organization Science, 16 (4): $409-421$. 